\title{
Prevalence of anaemia in patients discharged from the Paediatric Intensive Care Unit
}

\author{
Beatrice Allnut ${ }^{1}$, Simon Stanworth ${ }^{2,3,4}$, Samiran Ray ${ }^{1,5}$ \\ ${ }^{1}$ Paediatric and Neonatal Intensive Care Unit, Great Ormond Street Hospital NHS Trust, London UK \\ ${ }^{2}$ Transfusion Medicine, National Health Service (NHS) Blood and Transplant, Oxford, UK \\ ${ }^{3}$ Department of Haematology, Oxford University Hospitals, NHS Foundation Trust, Oxford, UK \\ ${ }^{4}$ Radcliffe Department of Medicine, University of Oxford, and Oxford BRC Haematology Theme, Oxford, UK \\ ${ }^{5}$ Respiratory, Critical Care and Anaesthesia Section, UCL GOSH Institute of Child Health, London UK
}

Corresponding author:

Dr Samiran Ray

Paediatric Intensive Care Unit,

Great Ormond Street Hospital,

London WC1N 3JH

Tel: 02074059200 ext 0218

e-mail: samiran.ray@gosh.nhs.uk

Dr Beatrice Allnut

beatrice.allnutt@nhs.net

Prof Simon Stanworth

simon.stanworth@nhsbt.nhs.uk

Running header:

Minimal fall in haemoglobin post-PICU admission 
Anaemia is prevalent in patients who are admitted to the paedaitric intensive care unit (PICU), increases during PICU stay and remains at PICU discharge (Bateman et al 2008; Demaret et al 2017). The adoption of evidence-based restrictive transfusion thresholds of $70 \mathrm{~g} / \mathrm{L}$ in stable PICU patients (Lacroix J et al 2007) has the potential to increase this burden of anaemia at PICU discharge. This may be relevant as a large proportion of children admitted to PICU have a complex chronic or life-limiting condition (Edwards JD et al 2012; Fraser L et al 2018), and have a high risk of anaemia at baseline. In addition, many PICU survivors are discharged with significant disability (Namachivayam P et al 2010): this poses a further risk of developing anaemia (Perenc $L$ et al 2015). Given the association between anaemia and adverse long-term outcomes (Larson et al 2019), it is important to recognise the prevalence of anaemia post-PICU in order to intervene and improve outcomes. One study reports follow-up data from children 6-months post PICU discharge that describes resolution of anaemia, but the numbers studied were small with a low follow-up rate (Ngo et al 2013).

While much of the focus has been on describing the prevalence of anaemia at PICU admission or PICU discharge, it is not known to what extent this persists to hospital discharge. It is possible that a restrictive transfusion strategy may no longer be followed within hospital outside PICU, especially in those children with complex chronic conditions. To explore this, we undertook a single-centre, retrospective observational study of haemoglobin levels $(\mathrm{Hb})$ discharged from a tertiary children's hospital following a PICU admission. We collected data on $\mathrm{Hb}$ levels in all patients (0-18 years) admitted to Great Ormond Street Hospital PICU over a 12-month period (1 $1^{\text {st }}$ January 2015 to $31^{\text {st }}$ December 2015) and discharged to a ward within the hospital. These children are more likely to have chronic illness, all needing ongoing tertiary-level specialty care. Data were collected at three timepoints - admission to PICU (T1), discharge from PICU (T2) and discharge from hospital (T3). Hb measurements taken closest to these time-points were used ( $\mathrm{Hb}$ measurements up to 12-hours prior to admission were considered). Anaemia was defined as $\mathrm{Hb}<2$ standard deviations below the ageassociated mean according to WHO reference ranges for normal Hb levels (Marks PW, Glader B 2009). The distribution of $\mathrm{Hb}$ at the three time-points was compared using the Friedman two-way ANOVA for ranks to account for non-parametric data (following a test for normality using the Shapiro-Wilks test).

Three-hundred and eighty-nine children were admitted to PICU and discharged to a ward within the hospital, with a median age of 14 months (inter-quartile range 1-70 months). Twelve children did not have $\mathrm{Hb}$ measurements during PICU - they were excluded from analysis. Overall, 224/377 (59.4\%) children had anaemia at $\mathrm{T} 1$, compared to $255 / 377(67.6 \%)$ at $\mathrm{T} 2$ and $235 / 377(62.3 \%)$ at $\mathrm{T} 3$. The $\mathrm{Hb}$ distribution was significantly different between the time-points following the Friedman two-way ANOVA ( $p$-value $=8 \times 10^{-5}$ ) (Figure 1). The median $\mathrm{Hb}$ decreased from 106.0g/L (IQR 91.0-127.0) at T1 to 100.0g/L (IQR 90.0-115.0) at T2, but increased to 102.0g/L (IQR 90.0-117.0) at T3 - although statistically significant, the median values are not clinically significantly different.

Anaemia is highly prevalent in PICU in the UK. There is an increase in rates of anaemia between PICU admission and discharge. However, $\mathrm{Hb}$ levels do not decrease further prior to hospital discharge in these children, nor is their evidence of a large increase to suggest 'top-up' transfusions post-PICU. This burden of anaemia persists until hospital discharge. We were not able to indicate in this study whether treatable causes of anaemia were appropriately recognized, nor whether treatment of anaemia was effective.

A restrictive transfusion strategy in PICU was adopted based on no difference in PICU outcomes (new or progressive multi-organ dysfunction during PICU stay) compared to a liberal transfusion strategy. With an increasing number of children surviving PICU stay, often with chronic morbidity, it is not known whether a consequence of the restrictive strategy in PICU has a bearing on long-term outcome 
in these children. Of note, TRIPICU (3) excluded many children who would be included in our cohort e.g. children with haemato-oncological disease and those post bone-marrow transplant. Several research questions follow, for example: (a) does the anaemia correct over time without affecting longer term health outcomes without any further treatment; (b) if not, can the treatment of anaemia mitigate these risks; and (c) what are the optimal tests to investigate causes for anaemia and guide appropriate treatment in the face of inflammatory illnesses and co-morbidities?

\section{References:}

Bateman ST, Lacroix J, Boven K, et al. Anemia, blood loss, and blood transfusions in North American children in the intensive care unit. Am J Respir Crit Care Med. 2008;178(1):26-33.

Demaret $\mathrm{P}$, Karam $\mathrm{O}$, Tucci $\mathrm{M}$, et al. Anemia at pediatric intensive care unit discharge: prevalence and risk markers. Ann Intensive Care. 2017;7(1):107. Published 2017 Oct 24.

Edwards JD, Houtrow AJ, Vasilevskis EE, et al. Chronic conditions among children admitted to U.S. pediatric intensive care units: their prevalence and impact on risk for mortality and prolonged length of stay*. Crit Care Med. 2012;40(7):2196-2203.

Fraser LK, Parslow R. Children with life-limiting conditions in paediatric intensive care units: a national cohort, data linkage study. Arch Dis Child. 2018;103(6):540-547.

Lacroix J, Hébert PC, Hutchison JS, et al. Transfusion strategies for patients in pediatric intensive care units. N Engl J Med. 2007;356(16):1609-1619

Larson LM, Kubes JN, Ramírez-Luzuriaga MJ, Khishen S, H Shankar A, Prado EL. Effects of increased hemoglobin on child growth, development, and disease: a systematic review and meta-analysis. Ann N Y Acad Sci. 2019 Aug;1450(1):83-104.

Marks PW, Glader B. Approach to Anemia in the Adult and Child. Hoffman F, Benz EJ, Shattil SJ, eds. Hematology: Basic Principles and Practice. 5th ed. Philadelphia, PA: Churchill Livingstone; 2009. Chap 34:439-46.

Namachivayam P, Shann F, Shekerdemian L, et al. Three decades of pediatric intensive care: Who was admitted, what happened in intensive care, and what happened afterward. Pediatr Crit Care Med. 2010;11(5):549-555.

Ngo QN, Matsui DM, Singh RN, Zelcer S, Kornecki A. Anemia among Pediatric Critical Care Survivors: Prevalence and Resolution. Crit Care Res Pract. 2013;2013:684361.

Perenc L, Przysada G, Trzeciak J. Cerebral Palsy in Children as a Risk Factor for Malnutrition. Ann Nutr Metab. 2015;66(4):224-232. 
Author Contributions: SS and SR devised the study plan, BA and SR collected and analysed the data. $B A, S S$ and SR contributed to the drafting of the manuscript. All three authors reviewed and edited the manuscript prior to submission.

Funding statement: This study received no direct funding but was supported by the NIHR Great Ormond Street Hospital and Oxford Biomedical Research Centres. The views expressed are those of the authors and not necessarily those of the NHS, the NIHR or the UK Department of Health.

Ethics: The study was approved by the Greta Ormond Street Hospital NHS Foundation Trust audit department. Individual patient consent was not sought as this was a service evaluation using routine clinically collected data. No patient identifiable data are presented.

\section{Figure 1:}

The distribution of haemoglobin levels at three time points in children admitted to PICU. Bean-plots showing the distribution of haemoglobin measurements at three defined time-points - PICU admission (T1), PICU discharge (T2) and hospital discharge (T3). A horizontal line in the bean plot denotes a data point, with the width of each line representing the number of data points with the same value. The overall shape of each bean plot represents the shape of the distribution. The horizontal dotted lines represent the median values of haemoglobin at the three time-points (106.0 $\mathrm{g} / \mathrm{L}$ for $\mathrm{T} 1,100.0 \mathrm{~g} / \mathrm{L}$ for $\mathrm{T} 2$ and $102.0 \mathrm{~g} / \mathrm{L}$ for T3). The x-axis shows the time in days starting at the time of admission to PICU. The blue vertical lines represent the median times for the T1, T2 and T3: T1 occurs at $0, \mathrm{~T} 2$ at a median of 4.1 days (IQR 2.2, 7.9 days) and T3 at a median of 23 days (IQR 11, 55 days). The bean plots are positioned according to when haemoglobin was measured relative to the three time-points: haemoglobin was measured at a median of 1 hour post admission (IQR $30 \mathrm{~min}, 3$ hours); a median of 22 hours before PICU discharge (IQR 10, 50 hours); and a median of 3 days prior to hospital discharge (IQR 1, 9 days). 